UDC $1: 35.082 .22$

LBC 87.701 .4

\title{
MOTIVES OF SOCIALLY RESPONSIBLE ACTIVITY: EXPLANATORY POTENTIAL OF THE HUMAN CAPITAL CONCEPT ${ }^{1}$
}

\author{
Tatyana S. Gorina \\ Volgograd State University, Volgograd, Russian Federation \\ Nina A. Kalashnikova \\ Volgograd State University, Volgograd, Russian Federation
}

\begin{abstract}
Modern interdisciplinary studies of human capital have allowed to change the understanding of its structure, incorporating not only the knowledge, skills, competencies and talents of the individual, but also his or her outlook, value attitudes, features of mentality and thinking in general. The concept of human capital makes it possible to identify various, including non-economic, motives of subjects of socially responsible activities, to understand why people are interested in implementing socially oriented programs. Socially responsible activities and human capital mutually condition each other: participation in socially responsible activities is an investment in human capital, and developed human capital is one of the conditions for effective socially responsible activities. The motives for socially responsible activities can be the desire to establish social justice, a desire to make the world more reliable and trustworthy, care for people, strengthen and spread social solidarity, increase the wellbeing of local communities, etc.Participation as a subject of socially responsible activities helps an individual to develop cognitive and social behavioral skills, provides access to information and practices necessary to adapt to the modern social environment. Socially responsible activity as a reflection of a specific system of thinking allows developing such important skills and qualities in modern society as purposefulness, empathy, willingness to take risks, independence in decision making, ability to work in a situation of uncertainty, ability to search for nonstandard solutions necessary for representatives of various specialties for successful implementation of professional functions, as well as contributing to the growth of the national economy. The advantages offered by socially responsible activities encourage individuals to participate in socially significant projects and companies, social institutions and society as a whole - to stimulate and support this kind of activity.
\end{abstract}

Key words: social responsibility, human capital, motive, system of values, moral qualities, critical thinking, social changes.

УДК 1:35.082.22

ББК 87.701 .4

МОТИВЫ СОЦИАЛЬНО ОТВЕТСТВЕННОЙ ДЕЯТЕЛЬНОСТИ: ОБЪЯСНИТЕЛЬНЫЙ ПОТЕНЦИАЛ КОНЦЕПЦИИ ЧЕЛОВЕЧЕСКОГО КАПИТАЛА ${ }^{1}$

\author{
Татьяна Сергеевна Горина \\ Волгоградский государственный университет, г. Волгоград, Российская Федерация \\ Нина Александровна Калашникова \\ Волгоградский государственный университет, г. Волгоград, Российская Федерация
}

Аннотация. Современные междисциплинарные исследования человеческого капитала позволили изменить представления о его структуре, включив в нее не только знания, навыки, компетенции и таланты индивида, но и его мировоззрение, ценностные установки, особенности менталитета и мышления в целом. 
Концепция человеческого капитала дает возможность выявить различные, в том числе неэкономические, мотивы субъектов социально ответственной деятельности, понять, почему люди заинтересованы в реализации социально ориентированных программ. Социально ответственная деятельность и человеческий капитал взаимообусловливают друг друга: участие в социально ответственной деятельности - это инвестиции в человеческий капитал, а развитый человеческий капитал - одно из условий эффективной социально ответственной деятельности. Мотивами социально ответственной деятельности могут стать стремление к утверждению социальной справедливости, желание сделать мир более надежным и заслуживающим доверия, забота о людях, укрепление и распространение социальной солидарности, повышение благополучия местных сообществ и т. д. Участие в качестве субъекта социально ответственной деятельности помогает индивиду сформировать когнитивные и социально-поведенческие навыки, обеспечивает доступ к информации и практикам, необходимым для адаптации к современной социальной среде. Социально ответственная деятельность как отражение специфического строя мышления позволяет развить такие важные в современном обществе навыки и качества, как целеустремленность, эмпатия, готовность идти на риск, самостоятельность в принятии решений, умение работать в ситуации неопределенности, способность к поиску нестандартных решений, необходимые представителям различных специальностей для успешной реализации профессиональных функций, а также способствующие росту национальной экономики. Преимущества, предоставляемые социально ответственной деятельностью, побуждают индивидов участвовать в социально значимых проектах, а компании, социальные институты, общество в целом - стимулировать и поддерживать такого рода активность.

Ключевые слова: социальная ответственность, человеческий капитал, мотив, система ценностей, моральные качества, критическое мышление, социальные изменения.

Интенсивность экономических, политических и культурных трансформаций современного российского общества порождает ряд социальных противоречий, требующих осмысления. Процессы модернизации, межкультурной интеграции, инновационного развития подразумевают, в качестве мировоззренческой основы, формирование определенной системы ценностей и строя мышления, которые зачастую противоречат ментальности и когнитивным предпочтениям россиян. Обозначенная ситуация может приводитьк нарастанию деструктивных и асоциальных форм поведения в российском обществе. В этом контексте актуальным становится исследование феномена социально ответственной деятельности через призму ее возможных мотивов, связанных с морально-ценностными и когнитивными ориентациями социальных субъектов. Изучение данного феномена является востребованным, поскольку его потенциал в области положительной социальной синергии в условиях современной российской действительности не реализуется. Социально ответственная деятельность нередко воспринимается как абстрактный элемент западной корпоративной культуры, а не как практический инструмент поддержания конструктивного диалога между властью, бизнесом и гражданским обществом с целью повышения каче- ства жизни как отдельного индивида, так и общества в целом.

На актуальность исследования указывает и дефицит концептуальных моделей, включающих мотивы социально ответственного поведения, особенно применительно к российской среде. В этом смысле обращение к теории человеческого капитала в ее современной междисциплинарной версии позволяет объяснить различные, в том числе и неэкономические, мотивы социально ответственного поведения.

В том или ином виде идея человеческого капитала уже присутствовала в классических работах А. Смита, К. Маркса, Ф. Энгельca, А. Маршалла, Дж. Милля. В самостоятельную теорию она превратилась благодаря деятельности Т. Шульца, Г. Беккера, В. Вейсборда и др. примерно во второй половине XX века. Т. Шульц связывал человеческий капитал с наличием у индивида знаний и умений, инвестиции в которые предоставляют человеку новые возможности и выбор. Человеческий капитал, согласно его теории, является важным фактором, способствующим экономическому росту, повышению уровня жизни [21]. Г. Беккер, разрабатывая данную концепцию, видел в качестве ее основной цели «изучение того, как производительность людей на рынке и вне его ме- 
няется под воздействием инвестиций в образование, квалификацию и пополнение знаний» $[1$, с. 584$]$. Однако «Т. Шульц и Г. Беккер уделили больше внимания тому, чтобы объяснить и отстоять идею равноправной с материальными ресурсами роли человеческого капитала в создании совокупного общественного продукта» [2, с. 638]. Такая позиция некоторым из современных отечественных исследователей представляется «излишне экономизированной» $[10$, с. 71$]$.

В настоящее время теория человеческого капитала приобретает междисциплинарный статус, на фоне чего меняется представление о структуре человеческого капитала в сторону ее расширительной трактовки. Он рассматривается как «знания, навыки, компетенции и другие качества, воплощенные в людях, которые способствуют созданию личного, социального и экономического благополучия» [22], а также как «интенсивный производительный и социальный фактор развития и жизнедеятельности субъекта, который неразрывно связан с человеком, с его интеллектом и менталитетом» $[7$, с. 4]. В структуру человеческого капитала, таким образом, могут быть включены не только знания, навыки, компетенции и таланты индивида, но и его мировоззрение, ценностные установки, особенности менталитета и мышления в целом.

Ряд авторов выделяет в качестве самостоятельного вида капитала морально-нравственный. По их мнению, он «представляет собой интегральную категорию, которая включает человеческий (трудовой, интеллектуальный капитал, капитал здоровья) и социальный капитал и определяется как совокупность морально-нравственных качеств экономических субъектов, способствующих формированию того или иного типа экономических отношений и определяющих эффективность использования других экономических ресурсов» $[10$, c. $77-78]$. При этом человеческий капитал аккумулирует в себе навыки, опыт, интеллект, образованность индивида, его состояние здоровья, трудовые и профессиональные знания, основанные на морально-нравственных качествах (бережливость, трудолюбие и т. п.) $[10$, c. $77-78]$, благодаря которым происходит как всестороннее развитие личности, так и рост уровня жизни на макро- и микроуровнях социальной системы. Данная интерпретация человеческого капитала представляется нам слишком «узкой», так как этот вид капитала, помимо морально-нравственных, включает и этически нейтральные компоненты. Попытка объединения человеческого и социального капитала в «интегральную категорию» также кажется не совсем обоснованной. На наш взгляд, морально-нравственный компонент является частью как человеческого, так и социального капитала.

Социально ответственная деятельность, в обозначенном контексте, и человеческий капитал взаимообусловливают друг друга: участие в социально ответственной деятельности - это инвестиции в человеческий капитал, а развитый человеческий капитал - одно из условий эффективной социально ответственной деятельности. Если рассматривать морально-этический аспект этого взаимодействия, то моральные качества индивида, являющиеся частью его человеческого капитала, могут побуждать индивида к социально ответственной деятельности, а последняя, в свою очередь, способствует закреплению и формированию определенных моральных качеств, а также построению соответствующей ценностной иерархии. Социальное одобрение может выступать не менее сильным стимулом, чем экономическая выгода, хотя неэкономические мотивы экономической деятельности не всегда являются очевидными.

Мотивами участия в социально ответственной деятельности могут стать стремление к утверждению социальной справедливости, желание сделать мир более надежным и заслуживающим доверия. Социально ответственная деятельность способствует созданию, укреплению, распространению социальной солидарности, делает ее более возможной. Многих участников такого рода деятельности объединяют схожие цели - забота о людях, повышение благополучия сообществ, в которых они живут. Социально ответственная деятельность показывает, что интересы отдельного человека могут быть согласованы с интересами группы, общества в целом.

Социально ориентированная деятельность основана на сопереживании, гуманизме, толерантности, сострадании, милосердии, альтруизме, уважении, благодарности, терпении, 
стойкости, признательности и т. п. По мнению Д. Паллотта, «благотворительность - это рынок, где товар - любовь» [4]. Создатели и пользователи платформы GoLocal, ориентированной на объединение двух целевых аудиторий в некоммерческом секторе - тех, кому срочно нужна помощь, и тех, кто готов ее оказать, - считают, что «доброжелательность, терпимость и честность - лучший способ в помощи другим» [16]. Поэтому, например, важно уметь выбирать средства достижения целей, способы деятельности, соответствующие требованиям морали.

Человеческий капитал, таким образом, при помощи социально ответственной деятельности может конвертироваться в капитал социальный, сущность которого «заключается в его выражении в качестве общественного блага: актор или акторы, создающие социальный капитал, обычно получают только малую его часть» $[8$, с. 138]. Социальная ответственность способствует нетворкингу, формированию сплоченных социальных сетей, повышению доверия к другим участникам социального взаимодействия; инвестиции в человека также позволяют достичь социальной справедливости.

Неэкономическая отдача от инвестиций в человеческий капитал включает в себя наряду с большей продолжительностью жизни, более крепким здоровьем, большим наслаждением от искусства и культуры, удовлетворенностью жизнью, повышением личного благополучия, расширением социальных связей, увеличением производительности индивида при выполнении нерыночной деятельности, повышением терпимости к социальному и культурному разнообразию, улучшением безопасности, увеличением социальной активности [12; 18]. Поэтому развитие и воспроизводство человеческого капитала высокого качества важно и выгодно как для индивида, который является его носителем и воплощением, так и для общества. Преимущества, предоставляемые социально ответственной деятельностью, побуждают индивидов участвовать в социально значимых проектах, а компании, социальные институты, общество в целом - стимулировать и поддерживать такого рода активность.

В отношении экономических выгод развитого человеческого капитала в его взаи- мосвязи с социально ответственной деятельностью отметим, что последний помогает в повышении дохода индивида, ускорении карьерного роста, повышении рентабельности фирмы, способствует росту национальной экономики $[1 ; 18]$. Современные изменения на рынке труда порождают спрос на новые навыки, знания, умения, которые формируются и обновляются как во время получения обязательного образования, на рабочем месте, так и за их пределами. Социально ответственная деятельность связана со всеми указанными сферами, являясь дополнительной возможностью приобретения новых компетенций, их адаптацией к требованиям социальной среды. Дж.Е. Ким, президент Группы Всемирного банка, считает, что для многих специальностей настоящего и будущего важны такие навыки, как сотрудничество, настойчивость, эмпатия [19]. Развитию этих навыков способствует социально ответственная деятельность. Участие в качестве ее субъекта позволяет индивиду сформировать когнитивные и социально-поведенческие навыки, обеспечивает доступ к информации и практикам, необходимым для адаптации к современной социальной среде, характеризующейся внедрением в жизнь и производство цифровых технологий, увеличением роли интеллектуального труда, изменением характера коммуникаций.

Социально ответственная деятельность, предполагающая модификацию существующих и поиск новых способов применения уже разработанных инструментов социальной помощи, развитие бизнес-структурами актуальных направлений социально преобразующих инвестиций, способствует формированию у ее субъектов инновационного мышления. Такое мышление связанно с творческой деятельностью и подразумевает «не только создание нового творческого продукта, но и его внедрение и продвижение» [9, с. 25].

Помимо глобальных проблем, для решения которых необходимы особые интеллектуальные возможности и моральные качества, компании должны реагировать на новые вызовы, связанные с изменением мышления местного сообщества: повышение требований со стороны населения к качеству окружающей среды; стремление людей, проживающих 
на территории присутствия компании, активно влиять на ход событий.

«Современные рыночные системы поощряют тот бизнес, который не только этично достигает основную цель - получение прибыли, но и вкладывает средства в реализацию социальных проектов, ориентируется на создание общественных ценностей. Активное распространение новой идеологии ведения бизнеса во многом обусловлено осознанием в предпринимательской среде простой истины: уровень экономического развития является в значительной мере производным от степени решения социальных проблем в данном обществе и состояния социальной сферы в целом» [14, с. 17]. Поэтому инновационное мышление как элемент социально ответственной деятельности также необходимо представителям бизнеса в условиях, когда требования к социальной нагрузке организаций со стороны общества растут, но у компаний нет финансовых ресурсов для расширения данного типа деятельности.

Одним из направлений социально ответственной деятельности является pro bono помощь - безвозмездные профессиональные услуги, позволяющие применить свои профессиональные навыки, знания, талант для квалифицированной помощи тем, кто в ней нуждается. Хорошо образованные, компетентные и при этом неравнодушные люди, добровольно участвующие в общественно-полезной деятельности, получают возможность «развития на практике таких навыков, как: лидерство, критическое мышление, коммуникация, презентация, управление временем» [3], и одновременно способствуют позитивным системным социальным изменениям. Компаниям корпоративное pro bono волонтерство позволяет создать позитивный общественный имидж, повысить привлекательность в качестве работодателя, лояльность сотрудников, доверие клиентов, подтвердить реальными действиями декларируемые ценности и, следовательно, повысить свою конкурентоспособность [20].

В условиях, когда роль информации сетевой коммуникации возрастает в геометрической прогрессии, очень важно уметь анализировать, оценивать ее и делать корректные выводы, что, в свою очередь, требует исполь- зования соответствующих когнитивных навыков, а именно - критического мышления, развитие которого происходит благодаря участию в социально ответственной деятельности, в том числе в pro bono деятельности. Когда реализуется модус критического мышления, происходит рефлексивная оценка как результата мыслительных процессов, так и его содержания, подвергаются сомнению стандартные модели восприятия и суждения. Это позволяет, в определенных пределах, преодолеть фрагментарность сознания, инертность мышления, противостоять многообразным манипулятивным воздействиям, активно применяемым в современных СМИ.

Критическое мышление предполагает применение следующих навыков: 1) связанных с восприятием и обработкой информации: оценка степени достоверности источников, поиск релевантной информации и ее последующий анализ; 2) логических, используемых в коммуникации и принятии решений: анализ и оценка убедительности аргументов и логической корректности выводов, практика вопросноответных процедур с целью уточнения информации и выявления возможных ошибок, четкость и ясность в изложении собственной точки зрения и адекватный выбор языковых средств, принятие решений на рациональной основе и обоснование своего выбора; 3) связанных с преодолением инерции мышления: умение воспринимать альтернативную позицию по рассматриваемой проблеме, учитывать различные подходы к ее анализу. Данная система суждений может быть рассмотрена как необходимый компонент создания благоприятного инновационного климата и важный элемент сознательного социально ответственного поведения с оценкой возможных рисков и прогнозированием последствий, что весьма актуально для успешного функционирования компаний и адаптации отдельных индивидов к быстро меняющимся условиям социальной среды.

Государство, инвестируя в человеческий капитал, проявляет заботу о своих гражданах, создает условия для равных возможностей разных групп населения, одновременно способствуя повышению производительности труда будущих поколений, росту национальной экономики. Поэтому органам государственно- 
го управления всех уровней выгодно сотрудничать с субъектами социально ответственной деятельности, организаторами социально ориентированных программ.

Однако социальная ответственность для ряда субъектов может быть связана с увеличением рисков, а потому требует развития знаний и навыков, которые позволят выявить потенциальные риски и разработать стратегию управления ими. Например, для бизнеса социальная ответственность означает повышение прозрачности, так как заинтересованные стороны, общественность ждут результатов, о которых компании сообщают, открыто и добровольно публикуя нефинансовые отчеты, содержащие важные сведения о разных направлениях активности компании. Открытость, честность перед стейкхолдерами позволят увеличить доверие к организации, сформируют позитивный имидж, повысят ее конкурентоспособность. Доверие - актив, который позволяет бизнесу получать больше прибыли [6].

Добровольный характер социальной ответственности означает, что для проявления такого рода активности нужны сознательные и стратегически мыслящие люди, которые понимают, что общим является не только будущее местного сообщества, города, региона, страны, но и всего человечества. Поэтому участие в социальных проектах помогает развить навыки, необходимые для оценки масштаба существующих социальных проблем, последствий при отказе решать эти проблемы сейчас, выработать представление об обществе будущего, чтобы реализовывать эту модель ежедневной деятельностью.

Социально ответственная деятельность позволяет получить более точные знания о мире, о социальной среде, в которой живет индивид, осознать значимость социальных и экологических проблем, благодаря чему реализуется познавательный мотив. С одной стороны, эффективная социальная ответственность предполагает, что участники замечают социальные проблемы, понимают, что проекты в области социальной ответственности это «продукты», которые решают или смягчают данные проблемы. Социально ответственная деятельность востребована, воспринимается как значимая, необходимая, когда социальные субъекты понимают, что она связана с решением проблем, с которыми человек сталкивается каждый день. С другой стороны, тем, кто стремится вовлечь как можно большее количество людей и структур (сотрудников компаний, местное сообщество, государство и т. п.) в социально значимую деятельность, необходимо разобраться в том, что происходит у потенциальных партнеров по социальной ответственности, определить их «боль», показав, какие важные для них проблемы решаются при помощи социально ответственной деятельности.

Участие в социальных проектах позволяет получить информацию о том, как и почему коммерческие и некоммерческие компании занимаются их реализацией. Отсутствие доверия к организаторам социально ответственной деятельности, к самой деятельности и ее результатам отчасти связано тем, что люди не понимают задач и преимуществ такой деятельности и структур, ее обеспечивающих (например, не знают, как работают некоммерческие организации), а потому не могут выработать критерии для их оценки. Так, в России благотворительность воспринимается как необязательные траты; основными барьерами для участия в благотворительной деятельности являются отсутствие финансовой возможности и стабильности, недоверие к благотворительным организациям [5]. Существующая система убеждений относительно этих организаций и некоммерческого сектора в целом также мешает изменять мир к лучшему [11]. Отказ от социально ответственной деятельности может быть основан и на устойчивых представлениях о человеке, согласно которым ведущим мотивом экономической деятельности является финансовая выгода, получение материальных благ.

Рекомендации, подготовленные $\mathrm{OOH}$, подсказывают, в каком направлении должно меняться мышление человека, который хочет сделать мир лучше. Важно знать, как повседневные действия людей влияют на окружающий мир, и понимать, каким образом обычный человек может минимизировать вред, причиняемый природе и обществу. Для этого нужно уметь работать с информацией («Проведите небольшое интернет-исследование и покупайте только у тех компаний, про которые 
вы знаете, что они используют экологически ответственные методы и не наносят вреда окружающей среде» [13]), быть активным, проявлять инициативу («Призывайте местные и национальные власти участвовать в инициативах, не наносящих вреда человеку или планете»; «Побуждайте вашу компанию взаимодействовать с гражданским обществом и искать способы для того, чтобы помочь местным общинам в достижении их целей» [13]).

Социальная ответственность помогает индивиду сделать свои решения более рациональными, обоснованными благодаря осознанию проблем, получению новой для него информации о мире. Так, сознательный потребитель оценивает эффективность благотворительных организаций, социального предпринимательства, не покупает товары компаний, загрязняющих окружающую среду, применяющих детский труд, участвующих в коррупционных схемах, нарушающих авторские права, несправедливо оплачивающих труд равной ценности. Г. Санжапова, социальный предприниматель, основатель Cocco Bello Honey, считает, что «человек покупает банку меда не только потому, что он вкусный, но и затем, чтобы изменить жизнь в стране» [15]. Потребитель, жертвователь в условиях отсутствия четких критериев оценки эффективности социально ориентированной деятельности должен уметь определить, является ли компания социально эффективной, приносит ли она заявленную пользу обществу. Хотя велико искушение сделать выводы о характере производства, оказываемых услугах лишь на основе заявлений, отчетов или рекламы компании.

Таким образом, социально ответственная деятельность повышает качество человеческого капитала, благодаря чему данная деятельность осуществляется более эффективно, так как для успешной реализации социальных проектов необходимы дополнительные знания, умения, некоторые из них требуют и развития определенного типа мышления. Возможно создание нормативной базы для социально ответственной деятельности (например, для исключения любых видов дискриминации, снижения выброса углерода в атмосферу, раздельного сбора мусора), однако многое зависит от способностей, навыков и мышления субъектов социально ответ- ственной деятельности в целом, ведь «мы создаем мир в соответствии с нашим мировоззрением» $[17$, с. 278$]$. В связи с этим важно, чтобы система ценностей, составляющая неотъемлемую часть мировоззрения, включала в себя уважение к человеческой жизни и свободе, прививала чувство ответственности не только за себя, но и за социальное и мировое целое.

Любые социальные изменения, как известно, - это, прежде всего, изменения, произошедшие в мышлении. Социально ответственная деятельность как отражение специфического строя мышления позволяет сформировать и усовершенствовать такие важные в современном обществе компетенции, как готовность идти на риск, настойчивость, целеустремленность, самостоятельность в принятии решений, умение работать в ситуации неопределенности, способность к поиску нестандартных решений, активизируя, тем самым, инновационный и критический модусы мышления.

Теория человеческого капитала, в ее современной интерпретации, дает возможность проследить как экономические мотивы социально ответственной деятельности субъектов, так и мотивы, связанные с мировоззренческими, морально-ценностными ориентациями и строем мышления. Финансовая и нефинансовая отдача от инвестиций в человеческий капитал делает очевидным тот факт, что индивидам и государству необходимо вкладывать ресурсы в его развитие. Индивид получает в дальнейшем отдачу от накопленного им человеческого капитала, однако результатами таких инвестиций могут пользоваться другие люди и общество в целом.

\section{ПРИМЕЧАНИЕ}

1 Работа выполнена при финансовой поддержке РФФИ и Администрации Волгоградской области, проект № 18-411-340013.

\section{СПИСОК ЛИТЕРАТУРЫ}

1. Беккер, Г. С. Человеческое поведение: экономический подход. Избранные труды по экономической теории / Г. С. Беккер. - М. : ГУ ВШЭ, 2003. $-671 \mathrm{c}$. 
2. Брик, Л. В. К вопросу о сущности понятия «человеческий капитал» / Л.В.Брик, А. Г. Горельцев // Вестник МГТУ. - 2014. - Т. 17, № 4. - С. 637-642.

3. Волонтерам // Todogood: Social change made simple $=$ Todogood: Платформа социальных изменений. - Электрон. текстовые дан. - Режим доступа: http://todogood.com/volunteer (дата обращения: 20.07.2018). - Загл. с экрана.

4. Дэн Паллотта: Мы в корне неправильно думаем о благотворительности! - Электрон. текстовые дан. - Режим доступа: https://www.ted.com/ talks/dan_pallotta_the_way_we_think_about charity_is_dead_wrong?language $=$ ru\#t-97576 (дата обращения: 18.08.2018). - Загл. с экрана.

5. Избыточное потребление и благотворительность // Фонд «Нужна помощь». - Электрон. текстовые дан. - Режим доступа: https://nuzhnapomosh.ru/ research/2017/izbytochnoe-potreblenie/ (дата обращения: 12.08.2018). - Загл. с экрана.

6. Кови мл., С. Скорость доверия: То, что меняет все / С. Кови мл., Р. Меррилл. - М. : Альпина Паблишер, 2018. - 425 с.

7. Корчагин, Ю. А. Российский человеческий капитал: фактор развития или деградации? / Ю. А. Корчагин. - Воронеж : ЦИРЭ, 2005. - 252 с.

8. Коулман, Дж. Капитал социальный и человеческий / Дж. Коулман // Общественные науки и современность. - 2001. - № 3. - С. 122-139.

9. Кубрушко, П. Ф. Формирование инновационного мышления студентов университета / П. Ф. Кубрушко, Л. И. Назарова // Вестник федерального государственного образовательного учреждения высшего профессионального образования «Московский государственный агроинженерный университет имени В.П. Горячкина». 2012. - № 4. - C. 25-28.

10. Нифаева, О. В. Морально-нравственные основы человеческого и социального капитала: проблемы терминологии и классификации / О. В. Нифаева // Креативная экономика. -2014. - Т. 8, № 9. C. $70-82$.

11. Паллота, Д. Неблаготворительность. Как ограничения работы НКО ослабляют их потенциал / Д. Паллота. - М. : Такие дела, 2017. -432 с.

12. Руководство по измерению человеческого капитала // ЕЭК ООН. - Нью-Йорк ; Женева : ООН, 2016. $-148 \mathrm{c}$.

13. Руководство по спасению мира для лентяев // Цели в области устойчивого развития. - Электрон. текстовые дан. - Режим доступа: https:// www.un.org/sustainabledevelopment/ru/takeaction/ (дата обращения: 14.08.2018). - Загл. с экрана.

14. Савичева, Е. Ю. К вопросу о дефиниции категории «социальная ответственность бизнеса» / Е. Ю. Савичева // Российское предпринимательство. - 2011. - Т. 12, № 8. - С. 17-22.
15. Шакирова, М. Добро за деньги: как заработать на социальном проекте / М. Шакирова // РБК. Электрон. текстовые дан. - Режим доступа: https:// www.rbc.ru/own_business/25/10/2018/5bcf28999a 794700b7c18e9f(дата обращения: 26.10.2018). - Загл. с экрана.

16. Этический кодекс пользователей GoLocalBot // Telegram-бот GoLocal. - Электрон. текстовые дан. Режим доступа: https://golocal. space/code (дата обращения: 25.08.2018). - Загл. с экрана.

17. Юнус, М. Создавая мир без бедности: Социальный бизнес и будущее капитализма / М. Юнус, А. Жоли. - М. : Альпина Паблишерз, 2009. - 307 с.

18. Human capital: How what you know shapes your life // OECD. - Electronic text data. - Mode of access: https://www.oecd.org/insights/humancapital howwhatyouknowshapesyourlife.htm (date of access: 24.07.2018). - Title from screen.

19. Kim, J. Y. Foreword // The Changing Nature of Work. - Electronic text data. - Mode of access: http:// documents.worldbank.org/curated/en/8162815188188144 23/pdf/2019-WDR-Report.pdf (date of access: 03.11.2018). - Title from screen.

20. Pro bono: российские практики и вектор развития. Аналитический отчет по результатам исследовательского проекта. - Электрон. текстовые дан. - Режим доступа: https://probono2017.ru/files/ Буклет_Pro_Bono_pyc_интерактивная.pdf(дата обращения: 21.08.2018). - Загл. с экрана.

21. Schultz, T. W. Investment in human capital. The role of education and of research / T. W. Schultz. - N. Y. : The Free Press ; L. : Collier-Macmillan Limited, 1971. $272 \mathrm{p}$.

22. The well-being of nations: The role of human and social capital // OECD. - Electronic text data. - Mode of access: http://www.oecd.org/site/worldforum/33703702. pdf (date of access: 21.07.2018). - Title from screen.

\section{REFERENCES}

1. Becker G.S. Chelovecheskoe povedenie: ekonomicheskiy podkhod. Izbrannye trudy po ekonomicheskoy teorii [Human Behavior. Economical Approach. Selected Works on Economic Theory]. Moscow, GU VSHE Publ., 2003. 671 p.

2. Brik L.V., Goreltsev A.G. K voprosu o sushchnosti ponyatiya «chelovecheskiy kapital» [On the Essence of the Concept 'Human Capital']. Vestnik $M G T U, 2014$, vol. 17, no. 4, pp. 637-642.

3. Volonteram [To the Volunteers]. Todogood: Platforma sotsialnykh izmeneniy [Todogood: Social Change Made Simple]. URL: http://todogood.com/ volunteer. (accessed 20 July 2018).

4. Den Pallotta: Myv korne nepravilno dumaem o blagotvoritelnosti! [Den Pallotta: The Way We Think 
about Charity Is Dead Wrong!]. URL: https://www. ted.com/talks/dan pallotta the way we think about_charity_is_dead_wrong?language $=$ ru\#t $-\bar{t}-9757 \overline{6}$ (accessed 18 August 2018).

5. Izbytochnoe potreblenie i blagotvoritelnost [Excess Consumption and Charity]. URL: https:// nuzhnapomosh.ru/research/2017/izbytochnoepotreblenie/ (accessed 12 August 2018).

6. Covey S.M.R., Merrill R. R. Skorost doveriya: To, chto menyaet vse [The Speed of Trust: The One Thing that Changes Everything]. Moscow, Alpina Publisher, 2018. 425 p.

7. Korchagin Yu.A. Rossiyskiy chelovecheskiy kapital: faktor razvitiya ili degradatsii? [Russian Human Capital: a Factor of Development or Degradation?]. Voronezh, TSIRE Publ., 2005. 252 p.

8. Coleman J. Kapital sotsialnyy i chelovecheskiy [Social and Human Capital]. Obshchestvennye nauki $i$ isovremennost, 2001, no. 3, pp. 122-139.

9. Kubrushko P.F., Nazarova L.I. Formirovanie innovatsionnogo myshleniya studentov universiteta [Formation of Innovative Thinking of University Students]. Vestnik federalnogo gosudarstvennogo obrazovatelnogo uchrezhdeniya vysshego professionalnogo obrazovaniya «Moskovskiy gosudarstvennyy agroinzhenernyy universitet imeni V.P. Goryachkina», 2012, no. 4, pp. 25-28.

10. Nifaeva O.V. Moralno-nravstvennye osnovy chelovecheskogo i sotsialnogo kapitala: problemy terminologii i klassifikatsii [The Moral and Ethical Foundations of Human and Social Capital: Problems of Terminology and Classification]. Kreativnaya ekonomika, 2014, vol. 8, no. 9, pp. 70-82.

11. Pallota D. Neblagotvoritelnost. Kak ogranicheniya raboty NKO oslablyayut ikh potentsial [Uncharitable: How Restraints on Nonprofits Undermine Their Potential]. Moscow, Takie dela Publ., 2017. 432 p.

12. Rukovodstvo po izmereniyu chelovecheskogo kapitala [Guide to Measuring Human Capital]. URL: https://www.unece.org/fileadmin/DAM/stats/ publications/2016/ECECESSTAT20166_R.pdf (accessed 18 August 2018).

13. Rukovodstvo po spaseniyu mira dlya lentyaev [The Lazy Person's Guide to Saving the
World]. URL: https://www.un.org/sustaina bledevelopment/ru/takeaction/ (accessed 14 August 2018).

14. Savicheva E.Yu. K voprosu o definitsii kategorii «sotsialnaya otvetstvennost biznesa» [On the Issue of Definition of the Category 'social Responsibility of Business']. Rossiyskoe predprinimatelstvo, 2011, vol. 12, no. 8, pp. 17-22.

15. Shakirova M. Dobro za dengi: kak zarabotat na sotsialnom proekte [Welcome for Money: How to Make Money on a Social Project]. URL: https://www. rbc.ru/own_business/25/10/2018/5bcf28999a $794700 \mathrm{~b} 7 \mathrm{c} 18 \mathrm{e} 9 \mathrm{f}$ (accessed 26 October 2018).

16. Eticheskiy kodeks polzovateley GoLocalBot [The Ethical Code of GoLocalBot Users]. Telegrambot GoLocal. URL: https://golocal.space/code (accessed 25 August 2018).

17. Yunus M., Jolis A. Sozdavaya mir bez bednosti: Sotsialnyy biznes i budushchee kapitalizma [Creating a World Without Poverty: Social Business and the Future of Capitalism]. Moscow, Alpina Publisher, 2009. 307 p.

18. Human Capital: How What You Know Shapes Your Life. URL: https://www.oecd.org/insights/ humancapitalhowwhatyouknowshapesyourlife.htm (accessed 24 July 2018).

19. Kim J.Y. Foreword. The Changing Nature of Work. URL: http://documents.worldbank.org/curated/ en/816281518818814423/pdf/2019-WDR-Report.pdf (accessed 3 November 2018).

20. Pro bono: rossiyskie praktiki $i$ vektor razvitiya. Analiticheskiy otchet po rezultatam issledovatelskogo proekta [Pro bono: Russian Practices and Development Vector. Analytical Report on the Results of a Research Project]. URL: https:// probono2017.ru/files/Буклет_Pro_Bono_pyc_ интерактивная.pdf(accessed 21 August 2018).

21. Schultz T.W. Investment in Human Capital. The Role of Education and of Research. New York, The Free Press; London, Collier-Macmillan Limited, 1971. $272 \mathrm{p}$.

22. The Well-Being of Nations: The role of Human and Social Capital. OECD. URL: http://www.oecd.org/ site/worldforum/33703702.pdf(accessed 21 July 2018).

\section{Information about the Authors}

Tatyana S. Gorina, Candidate of Sciences (Philosophy), Associate Professor, Department of Philosophy, Volgograd State University, Prosp. Universitetsky, 100, 400062 Volgograd, Russian Federation, tsgorina@gmail.com, socphil@volsu.ru.

Nina A. Kalashnikova, Candidate of Sciences (Philosophy), Associate Professor, Department of Philosophy, Volgograd State University, Prosp. Universitetsky, 100, 400062 Volgograd, Russian Federation, nika82@yandex.ru, socphil@volsu.ru. 


\section{Информация об авторах}

Татьяна Сергеевна Горина, кандидат философских наук, доцент кафедры философии, Волгоградский государственный университет, просп. Университетский, 100, 400062 г. Волгоград, Российская Федерация, tsgorina@gmail.com, socphil@volsu.ru.

Нина Александровна Калашникова, кандидат философских наук, доцент кафедры философии, Волгоградский государственный университет, просп. Университетский, 100, 400062 г. Волгоград, Российская Федерация, nika82@yandex.ru, socphil@volsu.ru. 